\title{
An ethical dilemma in child and adolescent psychiatry
}

\author{
P. J. Graham and D. M. Foreman
}

In this peper the ethiced concept of competience b oxplored in the contoxt of a very chellenging chlld poychlatiy case. Both mentel disorder and immotutly moy Impair a child's compotence. Howover, it is emphoutsed that competence is not a generic quellty but one thet should bo copilied to epecilic dections, oven when working with children.

\section{Case history (by Phillp Graham)}

Clare was an eight-year-old girl presenting with a pervastve refusal syndrome (Lask et al, 1991). Two months before admission she had suffered a viral infection with fever, cough and reduction in appetite. She recovered, but three weeks later suffered a cold and an ear infection. She gradually stopped cating and drinking and was admitted to hospital. No physical cause was found. Before admission to hospital, she had become quieter, less communicative and withdrawn. She had complained of muscle weakness and developed incontinence of urine and faeces. While in hospital she became completely mute and unable to walk. She was transferred to our specialist psychiatric unit, doubly incontinent, mute, fed by a naso-gastric tube and in a wheelchair.

Clare had previously been a bright, conscientious girl with an affectionate relationship with her parents and filends. She was doing well at school where she was thought to be unusually creative. No stressful events before the lllness were reported. The family background was unremarkable. She was the younger of two children. The family had moved from Scotland two years before admission because her father's firm had posted him to the south of England. The move had been resisted, though not very forctbly, by his wife and children, and it was clear that all the family, excepting father, would prefer to be back in Scotland.
However, this would have meant father leaving his firm and would possibly put the family into financial difficulties.

Treatment involved gentle encouragement on the ward to eat, walk and communicate more freely. This was supplemented by weekly family therapy sessions and weekly individual psychotherapy sessions with Clare. The therapy sessions did not produce material that would help us understand Clare's symptoms. However, over the first three months, Clare was weaned off her nasogastric tube and began to eat more normally, although she remained very picky. She gradually began to walk normally. Her incontinence ceased. Her communication improved and she spoke without difficulty, although not about anything that was troubling her. Arrangements were made for her to spend her weekends at home rather than at the local paediatric hospital where she had previously been spending weekends. However, at this point it became clear that Clare did not wish to return home, although she would not or could not say why.

Family interviews continued to be unrevealing, although there was a hint that father was involved in an extra-marital affair in Scotland. Individual sessions were similarly unfruitful. It was eventually decided, with her parent's agreement, that Clare would spend the day at home, regardless of her wish not to. She had to be forclbly taken home, and when there would kdck, scream, shout, attack the furniture, pull down curtains and swear at her parents. She battered them so that her mother returned after the weekend visibly physically bruised. She would not allow her mother to undress her or put her to bed and spent most of the night screaming and shouting before falling to sleep exhausted.

Case conferences were held with the representatives of the local social services department and with her parents' reluctant consent, it was eventually agreed that an 
alternattve weekend fostering placement would be found. There was, of course, much concern that Clare would not return home for good, realistic reasons. It was uppermost in our minds that she might have been abused. There was considerable disagreement in the team as to how far Clare should be forced to return home any more against her wishes.

Clare was initially quite positive about the foster placement but her eating became a problem there and weekend placement on the local paediatric ward was again instluted. However, she regressed on this ward at weekends and her incontinence returned.

The situation reached a plateau with Clare now refusing to speak to her parents without being able to indicate why. There was disagreement between team members as to how far the possibility of sexual abuse should be investigated. On the one hand, we had no evidence, other than Clare's unwillingness to talk to her parents, that she had been abused. She did use extremely bad language, but her play was not sexualised, and she did not really appear unusually sexually aware. Problems in the family relationships (espectally her father's controlling behaviour and her mother's passive way of showing hostlilty, linked to over-protectiveness of Clare) became more obvious, but were not particularly indicattve of abuse. She was offered several appointments with a member of our child sexual abuse team but refused to attend after one initial meeting. Disagreement between team members was resolved by open discussion.

When Clare began to show serlous relationship problems with the foster parents who found her highly manipulative and very difficult to cope with, especially in relation to eating, it seemed more likely that Clare's problems were intrapsychic and less Hikely that they were related to inappropriate parental care. Clare's symptoms now began to show for the first time a more typically anorexic quality.

About nine months after admission, the clinical picture changed to some degree in that Clare began to accept her parents' presence and to talk to them in a more normal way. However, the anorexdc features of her condition, food refusal, loss of weight and body image disturbance became more severe.

It was decided to transfer her to a unit specialising in children with anorexic disorders. Clare now said she did not want to go to this unit and wished to return home. She began to behave much more approprlately with her parents. However, it was decided that because her anorexdc behaviour had not really changed, she should nevertheless be transferred. She remained at the other unit over the next four months, during which time her weight stabilised and her relationship with her parents continued to improve. After several satisfactory weekends at home, she was discharged back to her family, who shortly afterwards moved back to Scotland.

The child's problems, although unusually severe, presented ethical dilemmas that are not at all uncommon in child and adolescent psychiatry. She showed behaviour that was really inexplicable on the information we possessed. Was she suffering from a mental illness, or was she reacting in an understandable way to family stress or were her problems due to a combination of these two possibilities? In trying, unsuccessfully as it turned out, to arrive at a conclusion, we faced ethical dilemmas relating to the intensity of investigation into sexual abuse or other traumas (itself a potentlally abustve intervention), and the need to work independently of her parents when our treatment philosophy relates very much to forming a therapeutic coalition with parents. Should we pursue the search for aetlology or focus on symptomatic relief?

\section{Commentary by D. M. Foreman}

Child and adolescent psychiatry raises important ethical questions for psychiatry in general. The duty of care to the child implies some duty of care to the child's family, as the latter are necessary to the child's well-being. This argument is also true for many patients who are cared for by their relatives. However, the child's (or patient's) and the family's interests may not always be aligned. Then, one may face decisions where conventional approaches to consent and autonomy are unhelpful. The question of where a child/ patient should live is one such example. First, as here, the wishes of the child/patient may not be in the child/patient's best interests. Secondly, there may be other children/patients in the family whose welfare may also be affected by the decision. Thirdly. damage to the family's welfare must be considered when evaluating the effect of the decision on the child/patient. This is a question of justice : what is a fair response to these conflicting demands? It would be interesting to know if the disagreements in 
the therapeutic team managing the case reflected this consideration. This series has already pointed out that we pay relatively little attention to justice in psychiatric ethics (Holmes et al, 1994). Professor Graham's case is further evidence that we need to correct this. However, any solution to such a complex matter is obviously beyond the scope of a brief commentary.

\section{References}

HoLmes, J., ADshrend, G. \& SMrth, J. (1994) An ethical dilemma in psychotherapy. Psychiatric Bulletton, 18, 466-468.
LASK, B., BrtTtEn, C., Krou, L. Magnana, J. \& Tranter, M. (1991) Children with pervastve refusal. Archtwes of Diseases of Childhood, 68, 866-869.

P. J. Graham, Emeritus Professor of Child Psychiatry, Behavioural Sclences Unit, Institute of Child Health, University of London, 30 Gullford Street, London WC1N 1EH and D. M. Foreman, Consultant/Senior Research Fellow in Child Adolescent Psychiatry, University of Keele, School of Postgraduate Medicine, Stoke-on-Trent ST4 7QB

\title{
Defeat Depression Campaign Fun Run
}

\author{
Sunday 9 April 1995 \\ 11 am, Battersea Park, London \\ Entry Fee $£ 3.00$ Distance 2 miles
}

Each entry fee will be matched by SmithKline Beecham and all proceeds will be put towards the funding of a

Defeat Depression Campaign educational package

For an entry form and sponsor form

please contact Christine Gear on 0712352351

A National Campaign organised by

The Royal College of Psychiatrists in association with

The Royal College of General Practitioners 